\title{
RESIDUAL SIGNAL AUTO-CORRELATION TO EVALUATE SPEECH IN PARKINSON'S DISEASE PATIENTS
}

\author{
José Carlos Pereira1, Arthur Oscar Schelp², Arlindo Neto Montagnoli, \\ Ana Rita Gatto 4 , André Augusto Spadotto5, Lídia Raquel de Carvalho ${ }^{6}$
}

\begin{abstract}
Objective: To evaluate the maximum residual signal auto-correlation also known as pitch amplitude (PA) values in patients with Parkinson's disease (PD) patients. Method: The signals of 21 Parkinson's patients were compared with 15 healthy individuals, divided according age and gender. Results: Statistical difference was seen between groups for PA, 0.39 for controls and 0.25 for PD. Normal value threshold was set as 0.3 ; $(p<0.001)$. In the Parkinson's group $80.77 \%$, and in the control group only $12.28 \%$, had a PA $<0.3$ demonstrating an association between these variables. The dispersion diagram for age and PA for PD individuals showed $p=0.01$ and $r=0.54$. There was no significant difference in relation to gender and PA between groups. Conclusion: The significant diff e rences in pitch's amplitude between PD patients and healthy individuals demonstrate the methods specificity. The results showed the need of prospective controlled studies to improve the use and indications of residual signal auto-correlation to evaluate speech in PD patients.
\end{abstract}

KEY WORDS: Parkinson's disease, speech analysis, residual signal.

\begin{abstract}
Auto-comelação do sinal residual para avaliação da fala em pacientes com doença de Parkinson
RESUMO - Objetivo: Avaliar autocorrelação do sinal residual também denominado como amplitude do pitch (PA) em pacientes com doença de Parkinson (PD). Método: Os valores de PA, estratificados de acordo com idade e sexo, em 21 pacientes com doença de Parkinson foram analisados e comparados aos dados obtidos em 15 indivíduos sadios. Resultados: Foi determinada diferença estatística para a PA entre os dois grupos ( $p<0,001 ; 0,39$ para os controles e 0,25 para $P D)$, considerando os valores normais como $>0,3$. Nos pacientes com PD $80,77 \%$ dos pacientes tinham a PA $<0,3$, enquanto que entre os controles somente $12,28 \%$ apresentavam valores abaixo de 0,3 . O diagrama de dispersão para idade e sexo para os doentes com PD mostraram um $p=0,001$ e $r=0,54$. Não houve diferença em relação a sexo e idade entre osgrupos. Conclusão: A significativa diferença da PA entre pacientes com PD e controles demonstra a especificidade da análise. Os resultados apontam para a necessidade de estudos controlados, prospectivos, para implementar o uso e indicações da determinação da amplitude do pitch na avaliação da fala em pacientes com doença de Parkinson.
\end{abstract}

PALAVRAS-CHAVE: doença de Parkinson, análise de fala, sinal residual.

Speech impediment is a consistent signal of bradykinesia, also known as akinesia, in Parkinson's disease (PD). Kinnier Wilson ${ }^{1}$ described it as a reduction in the frequency and amplitude of movements, easier seen in small muscles such as those involved in swallowing, writing, and speech. This dysfunction which affects more than $80 \%$ of PD patients ${ }^{2}$ has been called hypophonetic dysarthria, and consists of reduced vocal emphasis and variations in pitch and loudness with monotonous emission. Short periods of speech are intercalated by random pauses, with reduced or increased velocity. In colloquial speech, consonant articulation and syllabic repetition are poorly intelligible due to limited muscle movement. Difficulty with initiating speech (akinesia) could be observed as repetition of initial sounds. The voice is whispery and at times inaudible ${ }^{3}$. Electroglottography has not revealed significant diff e rences between PD

${ }^{1} \mathrm{PhD}$, School of Engineering of São Carlos, University of São Paulo (USP); ${ }^{2} \mathrm{PhD}$, Medicine School of Botucatu, State University of São Paulo (UNESP); ${ }^{3} \mathrm{PhD}$, Statistic, Applied Mathematics, and Computing, State University of São Paulo, Rio Claro (UNESP); ${ }^{4}$ Speech Therapist, Hospital of State University of São Paulo, Botucatu (UNESP); ${ }^{5} \mathrm{MSc}$, School of Engineering of São Carlos, University of São Paulo, São Carlos (USP); ${ }^{6} \mathrm{PhD}$, Bioscience School of Botucatu, State University of São Paulo (UNESP).

Received 28 April 2006, received in final form 28 June 2006. Accepted 4 August 2006.

Dr. Arthur Oscar Schelp - CP 540 - 18618-970 Botucatu SP - Brasil. E-mail: aschelp@fmb.unesp.br 
patients and healthy controls. Dynamic analyses of air current passage have shown increased glottis resistance, with a reduction in subglottal phonatory mean pressure, intensity and flow ${ }^{4}$. Fundamental frequency ( $F o$ ) analysis does not show differences between PD patients and controls ${ }^{4}$, whereas other authors have found elevated Fo in men compared to women ${ }^{5,6}$.

Subjective perception studies and those using instrumentation have shown limitations in pitch and loudness variability accompanied by breathiness, harshness, with reductions in loudness, mean intensity, and maximum phonatory frequency spectrum levels, at both the early and advanced stages of $\mathrm{PD}^{5,7}$.

Studies on residual signal, by voice signal inverse filtering and maximum residual signal auto-correlation value, called pitch amplitude (PA) ${ }^{8}$, allow us to hypothesize that we can evaluate the group of signals obtained from compromised laryngeal structures in PD in the absence of primary vocal fold dysfunction, with better or comparable sensitivity and specifity to subjective perception of the signs and symptoms of hypophonetic dysarthria in PD.

\section{METHOD}

The study was approved of by the Committee of Ethics in Research of the Botucatu Medical School included in main project named Establishment of Protocols and Therapeutics Options to Central origin Dysarthrophonies. Twenty-one Parkinson's patients were evaluated, independent of therapy. Nine were female and twelve male; ages ranged between 39 and 81 years. Patients were between II and III in Hoehn and Yarh stage ${ }^{9}$. They were analyzed about $2 \mathrm{~h}$ after having taken any anti-Parkinson's medication (i.e. dopamine replacement, dopaminergic agonists, and enzyme inhibitors). A control group included 15 healthy individuals without any current or prior history of otorhinolaryngological or neurological diseases. The inclusion cri-

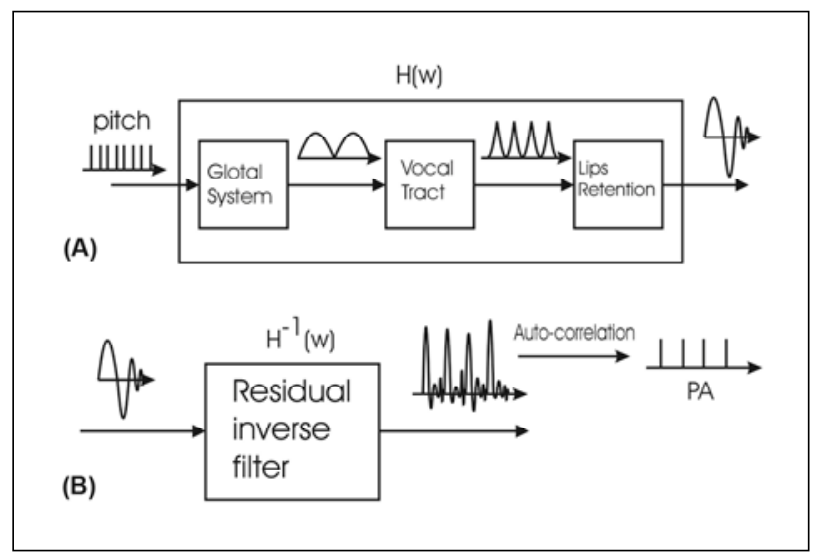

Fig 1. (A) Normal speech production, (B) inverse pathway. teria were to be non-smokers, and no alcohol abuser. This $g$ roup consisted of 6 males and 9 females between 21 and 60 years old.

Measurements of signals were made in a quiet environment directly on notebook and analyzed by Análise de Voz 2.3, a program developed by São Paulo University. The software determines: fundamental frequency (Fo), Jitter, Shimmer, Coefficient of Excess, Residual Spectral Smoothness, Inverse Filter Spectral Smoothness, Vocal Attack, Nasalization Index and Pitch Amplitude (PA). Pitch amplitude is an adimensional measure, quantified as the median amplitude of the second peak of residual signal self-correlation with normal values established as 0.3 according to Rosa et al. ${ }^{8}$. The pathway from which the signal was obtained is explained in Figure 1, where (a) shows the normal speech production and (b) the inverse pathway.

The phonation tasks were recorded from the emission of sustained oral vowel: /a/ and /il, with at least 6 seconds of duration.

Statistical analysis - Results are presented in the form of graphs. The chi squared test or Fisher's exact test were used to study associations between variables ${ }^{10}$. The Goodman test was used to compare proportions. Significance level was set at $5 \%$.

\section{RESULTS}

Statistical diffe rence was seen between groups for PA, 0.39 for controls and 0.25 for PD ( $<<0.001)$. In the Parkinson's group $80.77 \%$, and in the control group only $12.28 \%$, had a PA $<0.3$ demonstrating an association between these variables.

The dispersion diagram for age and PA for PD individuals showed $p=0.01$ and $r=0.54$. There were no significant diff e rences in relation to gender and PA between groups (Figs 2 and 3).

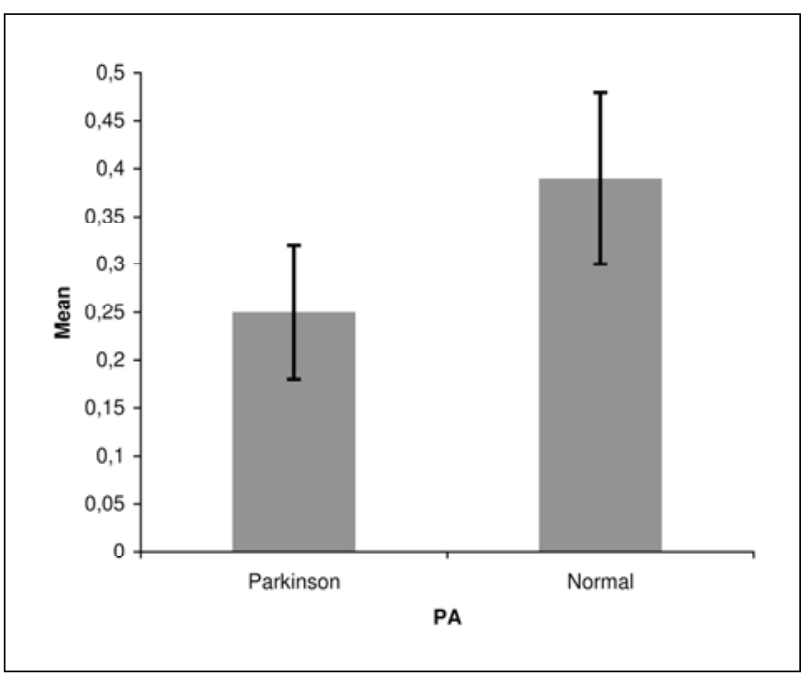

Fig 2. Mean and standard deviation for PA according to gro up $(p<0.001)$. 


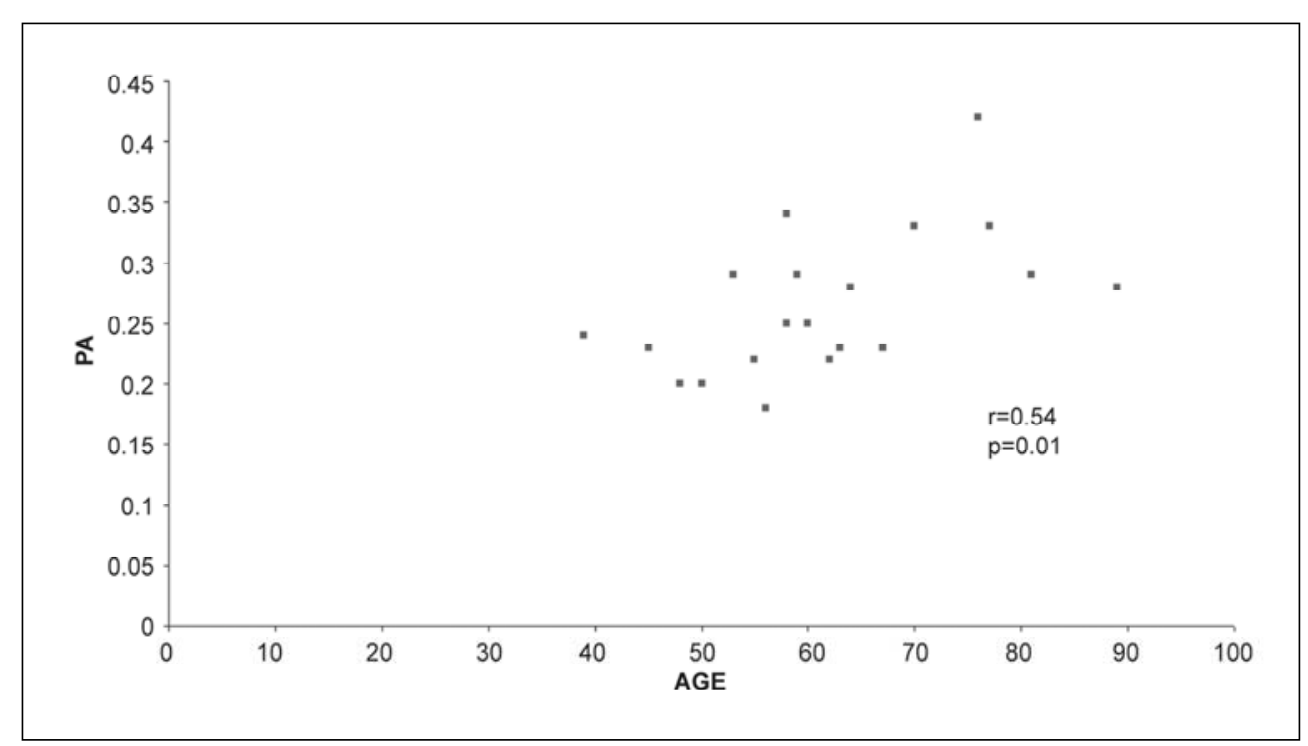

Fig 3. Dispersion diagram of age and PA for Parkinson's individuals.

\section{DISCUSSION}

Hypophonetic dysarthria is part of a group of signs and symptoms of Parkinson's disease; they can be identified as akinesia (loss of movement) or hypokinesia (reduction in the frequency and amplitude of small muscle movements, such as speech). The fail$u$ re to execute learned automatic movements could explain the clinical observation that Parkinson's patients do not efficiently execute sequential motor activities $^{11}$.

Subjective data, or rather the clinical examination is efficient in identifying the disease, but heterogenic recording is subject to variations depending on examiner, type of medication employed, posology, and time of day. Even having consensus that some voice parameters (breathiness, mono-pitch, mono-loudness, low loudness, and reduced maximum phonation frequency range) are poor, depending of volume and intensity of expelled air, with age and seriousness of diseases symptoms ${ }^{5}$, also there are discrepancies in the sensitivity levels of diff e rent functional grading scales for recording hypo-phonetic dysarthia in $\mathrm{PD}^{12}$. Common instrumentation methods are sensitive, but have low specificity in evaluating speech impediments in PD; this is demonstrated by the lack of differentiation between PD patients and contro Is for fundamental frequency $(F o)$, duty cycle $D C$, and closing time (CT) ${ }^{4}$, and also between before and after surgery for Fo, jitter and $P P Q$, shimmer and $A P Q$, and the harmonic to noise ratio (HNR), all obtained by sustained vocal emission, as in our study ${ }^{13}$. PA dispersion according to age was clearly concentrated in the
40-70 years age group - the group with the highest PD incidence, suggesting that residual signal analysis is not affected by age; this takes into account that patients were in the moderate to serious stage of the disease, independent of disease evolution time. The significant diffe rences in amplitude and pitch between PD patients and healthy individuals clearly demonstrate the method's sensitivity.

Another interesting result from our study was the lack of diff e rence between the genders in PA analysis, in both PD and healthy individuals. This is different to other authors who have reported increased portions of sub harmonic segments and more abrupt shifts in Fo in males ${ }^{6}$. Holmes et al. ${ }^{5}$, in 2000, had al ready shown that females in the latter stages of PD had a significantly more restricted maximum Fo than females in the early stages, while later stage PD males had higher minimum Fo than early stage males. Kent et al. ${ }^{14}$ reported elevated Fo values in men, analogous to results by Xue and Fucci ${ }^{15}$ who reported elevated values of peak amplitude variation (vAm), soft phonation index (SPI), smoothed amplitude pert u rbation quotient (SAPQ), and smoothed pitch pert u rbation quotient (sPPQ), considering the triad of $\mathrm{vFo}$, $\mathrm{VAm}$, and SPI as parameters which more consistently alter their form in male PD patients. This lack of co rrelation between genders for residual signal, but its correlation with disease symptoms suggests an even higher specificity for evaluating the distinct forms in which the disease manifests itself.

The results obtained from residual signal auto-correlation in PD patients indicates the sensitivity and 
probably the specificity of this method and highlights the need for more prospective controlled studies using different groups of patients under distinct therapy regimens, and in diffe rent evolutionary phases, to improve the significance of determination of pitch amplitude analysis for patients with Parkinson's disease.

\section{REFERENCES}

1. Wilson K. Paralysis agitans. In Ninian Bruce A. (ed), Neurology, $2^{\text {nd }}$. Ed. London: Butterworth \& Co LTD, 1954;922-940.

2. Logeman JA, Fisher HB, Boshes B, Blonsky ER. Frequency and cooccurrence of vocal tract dysfunctions in the speech of a large sample of Parkinson patients. J Speech Hear Disord 1978;43:47-57.

3. Darley FL, A ronson AE, Brown JR. Motor speech signs in neurologic disease. Med Clin N Am 1968;52:835-844.

4. Murdoch BE, Manning CY, Theodoros DG, Thompson EC. Laryngeal and phonatory dysfunction in Parkinson disease. Clin Linguist Phon 1997;11:245-266.

5. Holmes RJ, Oates JM, Phyland DJ, Hughes AJ. Voice characteristics in the prog ression of Parkinson's disease. Int J Lang Comm Dis 2000; 35:407-418.
6. Hertrich I, Ackermann H. Gender-specific vocal dysfunctions in Parkinson disease: electroglottographics and acoustic analyses. Ann Otol Rhinol Laryngol 1995;104:197-202.

7. Metter EJ, Hanson WR. Clinical and acoustical variability in hypokinetic dysarthria. J Comm Dis 1986;19:347-366.

8. Rosa MO, Pereira JC, Grellet M. Adaptive estimation of residue signal for voice pathology diagnosis. IEEE Trans Biomedical Eng 2000;47:96104.

9. Hoehn MM, Yahr MD. Parkinsonism: onset, progression and mortality. Neurology 1967;17:427-442.

10. Fisher LD, Belle GV. Biostatistics: a methodology for the health sciences. New York: Wiley-Interscience, 1993.

11. Marsden CD. Function of the basal ganglia as revealed by cognitive and motor disorders in Parkinson's disease. Can J Neurol Sci 1984; 11:129-135.

12. Stewart C, Winfield L, Hunt A, Bressman SB, Fahn S, Blitzer A, Brin MF. Speech dysfunction in early Parkinson's disease. Mov Dis 1995;10: 562-565.

13. Mourão LF, Aguiar PM C, Ferraz FAP, Behlau, MS, Ferraz HB. Acoustic voice assesment in Parkinson's disease patients submitted to posteroventral pallidotomy. Arq Neuropsiquiatr 2005;63:20-25.

14. Kent RD, Voeperian JF, Duffy JR. Voice dysfunction in dysarthria: aplication of the multi-dimensional voice program ${ }^{\mathrm{TM}}$. J Comm Dis 2003; 36:281-306.

15. Xue E, Fucci D. Effects of race and sex on acoustic features of voice analysis. Percept Mot Skills 2000;91:951-958. 